The Transparency Score is explained in New drugs: transparency, Vol 37 No 1, Aust Prescr 2014;37:27.

At the time the comment was prepared, information about this drug was available on the websites of the Food and Drug Administration in the USA, and the Therapeutic Goods Administration.

\title{
Update
}

\section{Antipsychotic switching tool [Update 3]}

Aust Prescr 2021;44:141

First published 16 June 2021

https://doi.org/10.18773/austprescr.2021.034

The online tool by Nicholas Keks et al has been updated. View updated tool (v4).

It includes a clarification that the paliperidone depot-to-depot advice applies to the once-monthly long-acting injection.

\section{EDITORIAL OFFICE}

For general correspondence such as Letters to the Editor, contact the Editor.

Postal The Editor

Australian Prescriber

GPO Box 266

Canberra, ACT 2600

Telephone +61282178700

Email info@australianprescriber.com

Website nps.org.au/australian-prescriber

Twitter@AustPrescriber

\section{SUBSCRIPTIONS}

Australian Prescriber is published every two months online. All content is accessible free of charge in full text at nps.org.au/ australian-prescriber. New drugs are published between issues as they become available.

An email alert can be sent to you when Australian Prescriber publishes new material. Subscribe or update your details at nps.org.au/australian-prescriber

For free copies of the Anaphylaxis wallchart and Switching-antidepressants poster, order online at www.nps.org.au/order\#for-health-professionals
(C) 2021 NPS MedicineWise ABN 61082034393

NPS MedicineWise Disclaimer Reasonable care is taken to provide accurate information at the time of creation. This information is not intended as a substitute for medical advice and should not be exclusively relied on to

manage or diagnose a medical condition. NPS MedicineWise disclaims all liability (including for negligence) for any loss, damage or injury resulting from reliance on or use of this information. 